\title{
SINDROMES CARENCIALES EN LA INFANCIA
}

Por el Prof. ARTURo SCROGgIE.

(Relator oficial sobre ef tema: Sindromes Carenciales).

Una variedad especial de cuadro nutritivo crónico lo constituye cierto grupo de sindromes carenciales de lactantes mayores de un año, en países donde el estado económico social y cultural del asalariado es bajo y las condiciones higiénico-sanitatias más. En consecuencia el estado de déficit nutritivo es motivado por las pésimas condiciones económicas de hogares con muchos hijos alimentados escasamente en cuanto a calidad y cantidad. Y por otro lado el medio ambiente insalubre representado por habitaciones estrechas, mal ventiladas y oscuras. con dos camas en las que pernoctan de cuatro a seis y más personas. Algunas ciudades y pueblos sin los recursos sanitarios más elementales, como alcantarillado, agua potable, incineración de desperdicios o basuras, medtos para exterminar los insectos, moscas. zancudos, etc.; requisitos sin los cuales no se puede evitar la pululación de agentes microbianos e infecciones que dan como resultado en un terreno deficitario una alta morbilidad.

Así planteado el problema podemos decir que estos sindromes se producen por dos causas. a saber: $10^{\circ}$ Por una dieta relativamente exenta de albúminas, grasas y vitaminas y sólo conteniendo escasas cantidades de hidratos de carbono y exceso de sal: 2." Por una alteración de la absorción de los elementos nutritivos y falta de aprovechamiento de éllos. $\mathrm{O}$ bien, por las dos causas unidas: régimen deficitario y falta de abscrción y aprovechamiento alimenticio.

Por estos mecanismos nos es dable observar una serie de modalidades clínicas que difieren del cuadro distrófico del niño mayor de seis meses, descrito por al Prof. Finkelstein, en su Tratado de Enfermedades del lLactante como así de la descomposición. de la cual no tiene sino en común en los casos más graves. la falta de absorción y aprovechamiento del alimento y su falta de síntomas anátomo-patológicos. 
La edad an que se inicia este cuadro carencial es desde un año hasta los cuatro y más años de vida. Se caracteriza en que fuera de los síntomas comunes a toda distrofia y acercándonos más, a la Distrofia Farinácea, no tiene con esta última sino el edema como sintoma afín: pero aun éste no tiene las mismas características, como ser la típica localización en bota o manguito; los otros síntomas son en relación del déficit carenciado. Este daño alimenticio y vitaminósico subclínico se yuxtapone o antagoniza y en consecuencia, raras veces observamos el dosencadenamiento de una Avitaminosis clínica ostensible y tipica. No podemos negar que observamos un raquitismo ligero o alteraciones del metabolismo calcio y fósforo. o que encontremos hematurias microscópicas, osteoporosis o sintomas pelagroideos como se les denomina a aquellas melanosis no bien caracterizadas. Tampoco podemos negar que en el curso de la mejoría venga a producirse una tetania o una diarrea grasa (esteatorrea) tipo sprue, etc. Todo nos comprueba rna poliavitaminosis subclínica que posiblemente será balanceada por el estado deficitario grave.

En este mecanismo defensivo al hambre en el mayorcito debe influir en primer lugar la edad. Ya de por sí entre los 1 y 4 años hay menos desarrollo y crecimiento, comparado con el menor; hay mayor defensa e inmunidad y alergia lo que está representando un mayor desarrollo del sistema reticulo-endotelial. Está capacitado adehás por la deambulación de apoderarse de restos alimenticios que no se le ofrendan. Por medio de monosílabos y de palabras puede expresar sus deseos y nececidades, saciar su hambre y sed. Se adapta mejor a la inanición que el manor de seis meses, conformándose con sus suerte, tornándose apático, estático, no se mueve, a lo cual sigue una inàpetencia que extraña. El clíma también influye para soportar el hambre prolongado, pues en latitudes en que el verano se extiende por seis meses como el nuestro, con un calor temperado, el déficit nutritivo es mucho mejor tolerado que en el invierno. Los primeros fríos a veces desencadenan los edemas carenciales en manguito y bota característicos. La relación de clima y avitaminosis ha sido recalcada por Moriquand para no insistir sobre ello.

La anamnesis nos sugiere datos de interés, impresionantes por las deficiencias del régímen dietético. Se trata de nacidos a término que después de una alimentación natural o artificial, a base de leche de vaca o succedánoos (leches deseca. das, condensadas, etc.), en el primer semestre de la vida, continúan esta misma dieta hasta el segundo semestre, sin que 
la ración se aumente de acuerdo con el desarrollo sino que por el contrario se disminuye o se cambia por el menor trastorno dispéptico e infeccioso del tractus intestinal a una dieta exclusivamente farinácea. O lo que es frecuente. sustitugen los biberones de leche por té con azúcar y unos dos caldos cen poco arroz y sémola. Pasado el primer año agregan a la anterior, ocasionalmente papas, zanahorias, más rato leguminosas, especialmente fréjoles. Debe citarse como una información de importancia que la comida de la noche es casi siem. pre la comida recalentada del mediodía. Pequeñas cantidades de pan pueden agregarse a este régimen y ocasionalmente frutas que recogen de los desperdicios o restos encontrados al azar. Se colige de lo anterior que la alimentación es pobre o falta en leche y grasas. No reciben carne, huevos, mantequilla, verduras ni frutas. Ocasionalmente leguminosas, papas y zanahorias recocidas, La base alimenticia es arroz, sémola, té, azúcar y cloruro de sodio.

La explicación de esta dieta irracional fuera de las razones expuestas de falta de cultura del pueblo en materia de alimentación y de no disponer los medios económicos para surtir el hogar de los alimentos básicos insustituibles por los aminoácidos que contienen (carne, leche, huevos. mantequi1ha, etc.), es la frecuencia durante los meses del calor de las infecciones enterocólicas y dispepsias. Estos trastornos traen como consecuencia una restricción que debía ser temporal de los alimentos a base de leche. Pero, en pueblos en donde está artaigada la nocividad de la leche de vaca en el verano o este medio nutritivo es la mala calidad o no existen medios para refuigerarla y en buen estado de consumo. se cae indefectiblemente en una cura hidrocarbonada y salina. Unos pocos se salvan y eluden aste ertor diético aceptando las leches curativas; albuminosa y babeurre y después usando leches condensadas o desecadas. Factor que se suma para gestar el cuadro deficitario es la cronicidad e intercurrencia de estas enterocolitis del verano, con lo cual los profanos padres, no apreciando el cuadro sino por las disposicionss van restringiendo poco a poco la alimentación hasta tener la satisfacción que con el hamb:e obtienen la mejoría del número y carácter de las heces. Asi se cae en este régimen carenciado que se mantienz durante más o menos seis meses, semestre de calor y falta de lluvias.

Si bien en otros la historia de su dieta anterior no nos extraña sino por la cantidad, su síndroma carencial nos los explicamos por causas endógenas. Estas son, la mayoría, infeciones del tubo digestivo que perturban la digestión y ab- 
sorción de los elementos nutritivos y aceleran el paso del quimo por un moto: ismo exagerado. Las infecciones pueden ser de la más variada naturaleza. Son todas aquellas que lesionan superficial o profundamente la mucosa intestinal y al mismo tiempo inhiben o restringen las secresiones digestivas; enterocolitis banales. gripales, disentéricas bacilares, amebiasis, salmonelosis y parasitosis intestinal. Conjuntamente con estas lesiones intestinales y a veces sin ellas, los ganglios mesenteriales están comprometidos e inflamados, lo que perturba la circulación del quilo y la absorción de las grasas. Es. te compromiso ganglionar es más profundo y grave en la tuberculosis mesentérica efectuando un verdadero bloqueo de la linfa. Se explica en consecuencia que los síndromas caren ciales sean más frecuentes en esta enfermedad. Uno de los órganos que tiene relación estrecha con el metabolismo y con la lalta de aprovechamiento y almacenamiento de los productos alimenticios es el hígado. Es así como muchos de estós cuadros presentan mayor o menor gravedad de acuerdo con el estado del parénquima o función hepática. Si éste esrá totalmente degenerado tenemos el cuadro caquéctico o $\mathrm{Ca}$ quexia. Todas aquellas infecciones generales como septice. mias, lues, tuberculosis, piurias, tifoideas, paratifus, etc., que repercuten su acción flogógena sobre el parenquima hepático pueden dar lugar a estas manifestaciones deficitarias. Se conprende que a ella se junte por la inapetencia o intolerancia, una alimentación como es lo más probable carencial.

Si las raciones alimenticias son escasas o mínimas en este síndrome la oferta en vitaminas va aparejada a las anteriozes. El factor liposoluble A no entra en la alimentación con arroz, sémola, y sólo se ofrendarían algunos carotenos en la zanahoria y otras legumbres que se ingerieran ocasionalmente. Lo mismo se aplica a la vitamina $D$. En cuanto a la vitamina B, su aporte sería casi nulo sobre la ebullición y reebullición de la semola y atroz. Sólo en el pan de harina serni-integral puede encontrar las dosis minimas infinitesimales que requiere con una alimentación hidrocarbonada $y$ grasa escasa. Sobre el resto del comple jo B creo que no está rcpresentadó en tan mínima dieta. La vitamina B sería suplida por las papas que de vez en cuando forman parte de la sopa o cazuela. Sólo el recalentamiento puede influir para aniquilar parte del ácido ascórbico que en el primer hervor, por el contrario, 10 aumenta aparentemente. De rodos modos debemos considerar que hay una oferta mínima de ácido cevitánico como es explicable por la dieta; como además, por las 
pruebas de saturación sanguinea que demuestran en forma fehaciente su déficit.

Si contamos la falta de alimentación privada de vitamiras y en su defecto el vaciamiento de sus reservas en los mayores de un año, el edema y alteraciones de la pared como de Ia absorción y motorismo del tubo gartro intestinal, la dismiaución de los fermencos digestivos y alteraciones de los ganglios mesentéricos y del hígado: y sumado a esto todavía las infecciones intercurrentes que nunca faltan en un organismo disérgico y aniquilado por el hambre. tendremos los factores básicos para la presentación de cuadros carenciales y poliavitaminósicos. Si las avitaminosis clásicas no se ostentan es porque seguramente la hipoalimentación impide el libre desencadenamiento de ellas. Esto se hace notorio cuando evoluciona hacia la mejoría el cuadro carencial y aparace el raquitismo florido, la tetania, diarreas de tipo sprue, etc. Es pata todos conocidos la relación entre raquitismo y sobre alimentación, entre beri-beri y alimentación exagerada de hidratos de carbono y alcohol. Por el contrario, la pelagra es común en los hipoalimentados y anoréxicos, en los reos de las cárceles o insanos en loquerías, etc. La xeroftalmia y keratomalacia también en distrofias alipogenéticas. No hay duda que hay o existe sinergismo y antagonismo entre ciertas vitaininas como asi también entr: éstas y ciertos elementos nutritivos. En consecuencia. de estas acciones resultan cuadros carenciados que no tienen ninguna sintomatología clá. sica. La relación dieta y las variadas vitaminas dan lugar a cuadros poliavitaminósicos o sindromes carenciales que difieren substancialmante de los conocidos y descritos en los tratados de pediatría: y este conjunto no despreciable de casos en ruestro pais, requiere un reconocimiento precoz para que los daños funcionales y orgánicos establecidos por ol hambre, no lleguen a un estado tal que hagan peligrat la vida del paciente.

Tenemos, pues, esbozados los mecanismos de producción de estos sindromes catenciales: $1 .{ }^{\circ}$ Inanición prolongada, relativa y absoluta, especialmente de albuminas y grasas; 2." Carencia temporal o prolongada de vitaminas: $30^{\circ}$ Infecciones del tubo gastro intestinal, enterocolitis subaguda y crónica o intercurrente. Debemos agregar aquí, diarreas de tipo carencial per dispepsia crónica o por infantilismo intestinal: 4. Alteraciones hepáticas o degeneraciones del parenquima por infecciones crónicas como tuberculosis, septicemias, piurias, nefritis intersticial. septicopiohemias, bronconeumonia 
post-morbilosa, coqueluche, sarna infectada, lúes, etc.; $5 .^{\circ}$ Adenitis mesentérica, infecciosas, banales o tuberculosas.

\section{Sintomatología}

Dentro del pleomorfismo sintomático de este sindrome carencial podemos distinguir por sus caracteres externòs dos tipos: $1 .{ }^{\circ}$ hiputrofia, y $2 .^{\circ}$ distrofia. Uno y otto difieren en grado y en la época en que se ha instituido el régimen de hambte.

Hipotrofia.-Se trata de seres prematuros y de término que desde el cuarto o quinto mes de la vida han estado sometidos a una alimentación escasa, incompleta e irracional. Muy poca leche y pocos agregados de hidratos de carbono. matizando posteriormente esta mala dieta con dos sopas con escasa cantidad de sémola o arroz y rabundante sal. Bajo el punto de vista social también tiene importancia el saber que se trata casi la mayoría de las veces de hijos de obreras o asalariadas, que dejan durante el dia al niño en su casa sin exponerlo a la luz solar y entrapujados en una forma tal de innovilización para que no se sienta ni haga ningún movimiento con las extremidades inferiores.

Como consecuencia de esta hipoalimentación ptolongada. mala higiene y estatismo, se nos presenta a la edad de un año o año y medio un ser que a la simple vista puede rubricarse como hipotrófico. Llama la atención su estatura, que es de 55 a 60 y un pocó más centímetros a la edad de un año. La circunferencia craneana de 42 y $43 \mathrm{cms}$. y las del tórax y abdomen notablemente disminuídas en relación con la primera. Si el abdomen a la simple vista aparece globuloso, este defecto no es sino ocasionado por una lordosis pronunciada. Lo que más resalta a la vista es el desarrollo de su cráneo y cintura escapular y brazos en relación con la pelvis y extremidades inferiores: la cintura pelviana es sumamente chica en relación con la escapular y hay una atrofia completa de las nalgas y extremidades inferiores. La distancia supraumbilical que a la edad de un año debe ser inferior en muchos centímetros a la infraumbilical, en estos casos hay igualcad de esta distancia o aun lo que es más anormal, un acortamiento pronunciado de las extremidades inferiores.

En estos niños la dentición extraña que no sea retardada y que sólo encontremos caries prematuras, un inducto yarduzco sobre el diente y pérdida de su esmalte. 
Otros síntomas que le son propios es el estatismo completo en que viven, pues al año y medio, a veces hasta los dos, pasan sentados en su cuna o cama o suelo, sin ejecutar ningún movimiento con las extremidades inferiores. Al levantarlos colgados debajo de los brazos presentan un reflejo de flexion del muslo sobre el abdomen y extensión de la pierna sobre el muslo, reflejo acondicionado a su posición estática y permanente. Al ejecutar el mismo acto anterior, se putede ver el aplanamiento del dorso de estos niños y casi la Verdade:a eventración lateral que se produce al conttaerse las rectos anteriores del abdomen.

Los reflejos en las extremidades inferiores son la mayo. ris de las veces débiles, en contraposición de los reflejos en los brazos, que se encuentran aumentados. Tomando la extremidad inferior por la rodilla y moviendo el pie, 1lama la atención la gtan hipotonía y cómo con qué facilidad se hace ejecutar movimientos de lateralidad al pie, tal como si fuera de trapo.

Por la disergia consiguiente, infecciones a repetición (gripales) y especialmente enterocolitis o dispepsias, traen como consecuencia, una dieta más rigurosa y iarente de leche $y$ viene a yuxtaponerse la misma sintomatología en el cuadro que denominamos de tipo distrófico.

Distrofia.-Se trata la mayoría de las veces de lactan. tes los cuales han estado sometidos en el segundo semestre de su vida a una dieta alimenticia minima, pero surtida y que a raíz de una infección en el verano se restringe aun más la alimentación a una dieta exclusivamente hidrocarbonada $y$ salina. Puede decirse que se trata primitivamente de un hipoalimentado con una distrofia farinácea de tipo hidrópico y que a ella se suma una sintomatología clínica atribuída a subavitaminosis agregada a esta inanición relativa de albúminas y grasas.

Los caracteres externos que los caracterizan son: cuadro de una distrofia grave, disminución de estatura y peso: del turgor de los tejidos. Anorexia marcada, dentadura en buen estado: desproporción en favor de los diámetros de la cabeza en relación con el tórax y abdomen. Gran hipotonía especialmento de las extremidades inferiores.

Estos, a diferencia de los anteriores, deambulan o han comenzado a deambular y luego de establecido el mal carencial han dejado de hacerlo. Además, son niños que ya han comenzado a articular monosílabos o hablan, a diferencia de 
los anteriores que, debido al aislamiento $y$ encierre en que han vivido, están en este respecto, bastante atrasados.

En este estado sobrevienen infecciones que no es raro que aparezcan en un terteno disérgico. Esto puede ser un estado gripal (rinofaringitis $u$ otitis) que repercute sobre el intestino, dando lugar a una diarrea. A la anorexia ya dicha, a los vómitos que se agregan y a la diarrea de diversa y variada naturaleza (gripal, disentérica, paratifus, salmonellas, tuberculosis, infecciones de la piel, sarna, impétigo, enfermedades infecto-contagiosas, sarampión, coqueluche y las bronconeumonias consiguientes) tenemos la tríada ideal (anorexia, vómitos, diarreas) para el régimen de inanición o hàmbre.

Así llegamos por esta otra via al síndrome carencial. In cl capítulo anterior se hizo un resumen en el cual se exponia los distintos factores que podían conducir al mismo fin.

\section{Sintomatclogía común de estos sindromes carenciales}

Psíquis, sistema nerviosc y aparato locomotor.-Resalta en estos cuadros la facie característica. Una cara de máscará inexpresiva, la cual sólo es interrumpida por accesos de llanto o rabia, muchas veces inmotivado. Cuando se les observa en una sala sin que ellos se den cuenta, no prestan ningún interés a lo que les rodea ni tampoco a los juegos o juguetes de sus vecinos. Hay una indiferencia o apatía absoluta. Sólc al ver a veces la mamadera, se molestan y reciben a la enfermera que los va a alimentar, con náuseas y muestras de desagtado, como llanto.

Hay que darles el alimento con cuchara y a la fuerza en los primeros momentos, pues no quieren recibir nada. Só10 aquellos que hablan piden cierto tipo de plato alimenticio que el médico creía anteriormente conveniente no darlo. Asi. hay unos que gimen por pan, otros por melón o sandía. cazuela, papas fritas u otros platos por el estito. Es en consecuentia, una anorexia caprichosa y neurótica; a veces, cuando se deja frente al niño un plato con varios alimentós y la enfermera se encuentra lejos, ellos de por sí, con la mano, escogen aquel que desean y les conviene. Se trata de una inapetencia a las dietas curativas y a la alimentación que antes se les ofrendaba y por otro lado, una tesistencia a la madre o enfermera que quiera dartes la alimentación con cuchara $y$ tenedor, o sea, con los medios usuales. $Y$ además, 
tal como el animal, él mismo con sus manos come lo que su organismo y déficit le piden. En esta forma hemos logrado vencer la inapetencia, que era el escollo más difícil a salvar en estos casos.

Asi, un caso en que no quiso tomar ninguna mamadera a base de leche $y$ harinas de todas clases y preparadas en rodas las formas, sólo aceptó lo que él pedía con insistencia, que era un café con leche.

El insomnio es otro síntoma marcado, pasan el día y la noche con los ojos entreabiertos, con la apatía e indiferencia ya anunciada y sólo rasgan la muralla o el suelo donde se encuentran para llevarse trozos de tierra o de papel a la boca. como así también en orras ocasiones, hasta insectos que ellos degluten y comen.

Gimen y lloran durante toda la noche. Se orinan y defecan, no controlando sus esfínteres, hecho que llama la atención. pues antes de caer en este sindrome carencial, tenían algunos perfecto control de su vejiga y recto.

La estática-dinámica, como ya se dijo. se perturba grandemente al iniciarse este cuadro. Si antes andaban, primero se quejan de cansancio; esto es un signo notorio, ya no desean gatear ni andar, sino que permanecer sentados, estáticos, apátiços y sólo royendo un pedazo de pan o un trozo de tierra o un pedazo de madera o papel. No les gusta exponerse al sol, sino que buscan la sombra para pasar todo el día en un mismo punto.

La hipotonía ya se hace manifiesta y estả en relación con una relajación ligamentosa $y$ un estado de laxitud y atrofia de la musculatura. La fuerza muscular decae y junto con éstor trastornos vasomotores, como enfriamiento $y$ cianosis o toIor rosado azulejo de las extremidades. La musculatura se atrofia especialmente en la región glutea, en donde la piel forma grandes pliegues. En las extremidades inferiotes, la palpación de los músculos da la sensación que hubieran desapirecidos y que sólo la piel edematosa o gruesa rueda bajo los dedos.

Ya también junto a la hipotonía se presentan cuadros catatónicos y tendencia a las convulsiones o ataque eclámptico ante una infección indeterminada. En muchos de eilos encontramos sintomas de hiperexcitabilidad del sistema netvieso, como signos de espasmofilia, Chrosteck, Lust. Trous$\therefore r_{1}$ Schlessinger-Pool, Erb y Cronaxia. Este mismo factor está condicionado, como se verá más adelante, por la hipocalcemia, hipofosfemia y disminución del magnesio. Po: otro 
1ado debe influir el exceso de sales de sodio y relativo de potasio.

Los reflejos en las extremidades superiores marcados, exagerados; bicipital, radial y supinador. En las extremidades inferiores, los reflejos varian: unas veces exagerados, otras abolidos, especialmente cuando hay marcado edema. No sé si explicar a veces esta falta de reflejos por la gran imbibición acuosa o por existir una verdadera neuritis.

Piel.- No hay órgano que refleje con mayor precisión e' estado de nutrición de un individuo que la piel. Esto se hace extensivo también a los animales y especialmente a los artimales de experimentación. en los cuales las alteraciones de esta parte del organismo da lugar por los distintos regímenes carentes de vitaminas a las discusiones más acalotadas.

Para la mayor comprensión de la sintomatología en nuestra población infantil, es necesario tenér una idea de la coloración, consistencia y reacción de la piel del niño ante la acción de la lụz solar, del frío, del calor y a la acción tóxica de la carencia en alimentos y vitaminas romo así a la acción tóxica de ciertos medicamentos. Nuestra raza es de cierta homogeneidad y el nativo presenta una piel de color moreno y entre la gente de las clases media y alta. el tinte es un moreno pálido o blanco. Es en esta última donde se pueden apreciar con más facilidad los pormenores de procésos infecciosos. tóxicos a carentes que van a repercutir sobre esta envoltura.

Lo primero que llama la atención en niños carenciados es que su piel se torna más oscura; este oscurecimiento no es homogéneo, sino que más intenso como se comprende, en las partés expuestas al sol. Junto con la hiperpigmentación tenemos también la sequedad, la aspereza de este órgano que tefleja su hipoalimentación. También tenemos el cuadro de la infiltración de la piel manifestado por su hiperexudación y pruzito y en periodos más avanzados por eczema y neurodermitis. Luego tenemos, seborreas, descamaciones, hipertricosis, trofismo de la piel que junto a las infecciones, como sarna, impérigo y jiodermitis, forunculosis y acné. forman el cuadto más nutrido de estos síntomas.

Analizaré aisladamente cada uno de ellos.

Hiperpigmentación o Melanosis.-Muchos cuadros pueden presentarse con el aumento de pigmentación de la piel. Típico de ello es la enfermedad de Addisson o insuficiencia de la cápsula supratrenal. A este órgano además, se le ha atribuido una relación con la pigmentación de la piel y las 
cápsulas suprarrenales y la avitaminosis C. Además, anonialias pigmentarias y hepáticas como la acropigmentación idiotípica y la acropigmentación simétrica de Dohl. También la enfermedad de Safo (Matsunaga). Esta última es una enfe:medad de coloración de la piel de las extremidades superiores e inforiores en las islas Truk en el Mar del Sur, es hereditaria; la mancha mongólica y la mancha gris, efelides; nevis. el nevis pigmentario de la enfermedad de Recklinghausent. e] nevis moluscoideo, melanosis cori degenerativa, etc.

Sobre la acción del sol en la piel debemos reconocer que existen anomalías pigmentarias paratípicas, así la dermitis de Berlock en que se producen manchas parduzcas como de formas de listas, después de baños de mar o al usar en la piel agua de colonia. Esta pigmentación viene posteriomente a un proceso inflamatorio de rubicundez la cual viene a dar la coloración parduzca pigmentaria.

Sabemos la acción del sol sobre la piel de diversos indivíducs, transformándcse luego después de esta exposición en un eritema o dermatitis solar. La evolución de ella puede ser una pigmeatación homogénea de la piel o como pasa en otros. a la formación de pecas. Según la sensibilidad individual, a la luz solar las partes no cubiertas por el vestido se pigmentan en mayor o menor grado. La pigmentación puede también sobrevenir por el calor y presentarse lo que se llama la cutis marmcrata pigmentosa de Buschke-Eichhorn o melanosis por el calor. Entre nosotros, la gente del pueblo presenta con frecuencia esta manifestación clínica en la payte antero-interna de las piernas, rodillas $y$ muslos; por efecto del calor del brasero durante el invierno. También la pigmentación a raíz de quemaduras por fuego, debemos tomarla en consideración para el diagnóstico de estas melanosis carenciales. Hay también melanosis que pueden producirse por estimulos químicos, ya sean locales o por ingestión, como yodo. plata, oro $e$ inhalación de gases; las melanodermias locales por estimulos, ya sea por aplicación de mostaza, cantárides, aplicactiones de crisarobina, alquitrán, aceite de bergamota, etc. Enfermedades más raras y que tienen relación con la pigme:1tación de la piel tenemos la xerodermia pigmentosa tan peculiar en el niño, la melanodermatitis tóxica bulósa, cuyo diagnóstico con la pelagra es difícil de establecer. Ahora, es necesario tener además presente la dermitis tóxica del sulfothiazol por la pigmentación y descamación. La melanosis de Riehl cuya naturaleza no es clara se presenta especialmente en la cara con una inflamación folicular que después se pigmen- 
ta y descama, tratándose de una simple hiperhemia porque faltan síntomas de inflamación y su extensión al cuerpo. Después de eczemas y su atención con alquitrán puede perdurax un color pigmentado. Si hay cicatrices y se efloresce se llama Mplanoderma. Recordar el Cloasma de las embarazadas La dermatosis pigmentada alrededor de la boca que dosaparece con la presión de la lupa. La melanodermia pediculosa, 11amada también la piel del vagabundo, la cual deja libre la cara y brazos; es curiosa que presenten también manchas pigrinentarias en la parte mucosa de la mejilla; la piel tiene un color oscuro y secciones de ella hipocrómicas en telación con efectos de grataje infestados. También en infecciones de la piel como acné, puede quedar la pigmentación. En las leucemias $y$ enfermedad de Hodgkins puede observarse estas melanodermias. Las eflorescencias de psoriasis, liquen ruber. pueden curar dejando esta pigmentación. Pigmentaciones localizadas se cbservan en aquellos focos en regresión de la $\mathrm{mi}$ cosis fungoide. de1 pénfigo, de la peridermolisis bulosa, eritema exudativo multiforme y también pigmentaciones de la mucosa. A veces enfermedades de la piel con intenso prurito da lugar al aumento del pigmento como ser en la dermatitis herpetiforme de Duhring. También en el Herpes gestaciones y en el Herpes Zoster pueden presentarse aquellas tendencias. En la sifilis tenenros un aumento considerable del pigmento, ya sabemos en el niño el color café con leche de la cara y hasta intensamente moreno, ocre; las cicatrices luéticas siempre dejan un balo pigmentado,

La revisión que se ba hecho de todas las anomalías pig. mentarias de la piel tienen por objeto tenerlas en vista al describir los verdaderos cuadros que nosotros observamos.

En estos niños se produce la hiperpigmentación junto con una sequedad y aspereza de la piel. Hay unz intensidad en la coloración en el dorso de las manos. mitad anteroexterna del antebrazo y externa del brazo, después del cuello perfectamente bien delimitadc cor una extensión hacia el esternón y hacia las apófisis espinosas de la columna. También en el dorso del pie y cara anteroexterna de la pierna y que se extiende hacia el muslo, desapareciendo en forma lenta y gra. duada. No hay demarcación neta, salvo en la parte posterior del cuello en correspondencia a la camisa o chaqueta o parte cubierta. En la cara puede notarse un aumento tegular de la pigmentación con un color ligeramente rosado. Examinando con cuidado y flectando la mano sobre el antebrazo, se aprecia que las fisuras normales entre las escamas de la piel son 
más pronunciadas y profundas y de un color que contrasta con la losange escamosa intensamente pigmentada. Esto hace aparentar como si fuera una ictiosos o simula la piel de un lagarto. En la región de la mejilla, este color de hiperpigmentación puede presentarse en zonas pequeñas, como sucias, rodeadas de partes más blancas. En resumen, existe una simetria perfecta en estas zonas hiperpigmentadas, su localización es casi siempre igual y puede presentarse en mayor o menor grado de intensidad. Interesante es observar zonas leucodétmicas o hipocrómicas que pueden estar en relación con infecciones impetiginosas ya cicatrizadas o con sarna en estado de actividad o ya en regresión. Otras veces, estas zonas hipocrómicas representan verdaderos cuadros de vitiligo, síntomas que han sido descritos especialmente por Merck y Jadaschn como típices de la pelagra en el Handbuch der Haut und Geschlechtskrankheiten y que se pueden encontrar ade más en los cuadros de las Melanodermias del Vagabundo, tal como se ha dicho anteriormente (Meirowsky).

El Prof. Alballí y Castellanos han descrito los mismos tipos en el niño en Cuba y los han denominado Pelagroides. La evolución de estos casos en que con una dieta completa desaparece luego esta hiperpigmentación y además, observándolos en níños mayores, en los cuales se va poco a poco demarçando más esta pigmentación unida a una dermatosis, las considero que son tipos de pelagra frustra o suave. Me baso principalmente por el examen histopatológico que revela una biperqueratosis, a veces una paraqueratosis, atroria de la piel. hiperpigmentación en la red malpigiana e infiltración en el corion con infiltración además perivascular.

Una vez pasada la coloración intensa de la piel, deja ana superficie suave, aterciopelada. como si existiera una atrofia, taansparencia de la piel dejando entrever con claridad las venas y vasos del cutis.

Hiperqueratosis. - La hiperqueratosis es el signo corriente en estos cuadros carenciales. No me refiero a iiertos tipos comunes y familiares de queratosis pilar, sino a que aquí existe una hiperqueratosis folicular en un comienzo, en otros términos hay eflorescencias córneas cutáneas que le dan sersación de aspereza y rugosidad a la piel. Sitios de prefe. rencia de esta hiperqueratosis lo son aquellos puntos donde la hiperpigmentación es más ostensible. pero afectan todas las superficies del cuerpo. En su primer período as el tipo de hiperqueratosis folicular que se encuentra en casos de fieore tifoidea después de la tercera o cuarta semana; luego después 
se hace más acentuada hasta formarse grandes escamas, espesas, con aumento de la pigmentación dándole un aspecto de suciedad. Estas escamas, como he dicho, son más intensas y visibles en las regiones expuestas al sol o donde ya previamerté existía esa hiperpigmentación, pero es en el cuero cabelludo donde esta hiperqueratosis aunada a una ligera seburrea es más ostensible. Al pasar la mano se aprecia lia aspereza, sequedad del cuero cabelludo junto con fenómenos tróficos que se observan como la caida del pelo o pelo raleado. En la cara esta descamación va a patejas con la hiperpigmentación y en algunos casos más raros se ven acumulaciones sebáceas y fisuras de la boca (Queilosis).

Esta hiperqueratosis se aprecia fácilmente cuando no lo es a la simple vista haciendo un rascado superficial en la región dorsal, en la raíz del cuello, produciéndose una linza blañca que no desaparece a los 10 a 15 minutos como ordinario, sino que dura a veces hasta 12 a 16 horas. Esta hiperqueratosis es perfectamente comprobable además por el microscopio, como puede verse en los cortes histopatológicos y junto a ésta hay además en algunos casos una paraqueratosis. Muy interesantes son ciertos bolos de cuerpos queratinizados que se encuentran incluidos en la piel y que Jadassobn ha denominado hiperqueratosis intrafolicular atribuyéndolas a la pelagra; según otros a] escorbuto, como lo demostró expe:imentalmente un estudiante de medicina de Boston, el cuai durante 6 meses estuvo sometido a una dieta libre de vilamina $C$ y a los 161 días aparecieron pápulas hiperqueratóticas que después dieron lugar a hemorragias perifolictlares. El ácido ascórbico no se logró dosifisar en el plasma durante trece semanas antes que apareciera la primera cvidencia de escorbuto clínico. Según otros, Rapapport, estas inclusiones hiperqueratóticas foliculares serian debido a la avitaminosis A.

Las infecciones secundarias de la piel, como sarna, impétigo, por la biperqueratosis afloran de la superficie con mayor intensidad que en una piel sana. Después al regresar se produce un balo pigmentado y una zona leucodérmica de la cual se ha hecho mención.

En el periodo de la curación la destamación se hace notoria, franca, a grandes trozos y comprende todo el cuerpo, pero especialmente marcada en las zonas edematosas.

Un becho que extraña en estos cuadros es la hipertricosis: algunos muy acentuados, presentando un vello que cubre tedo su cuerpo, otros se les aprecia especialmente en la cara, 
delante de las orejas y borde posterior del maxilar formando verdaderas patillas. Este vello la mayoría de las veces es de un tinte oscuro. Este pelo, a medida que va mejorando las condiciones de nutrición toma un culor claro en la punta que parece casi como oxigenado y se le puede comparar con el pelo de liébre. oscuro en la base y rubio en la punta. Es tan característico este cambio de coloración que una vez dados de alta del Hospital y vueltos a sus casas a tener una alimentación carenciada, el proceso de oscurecimiento vuelve a producirse. Si analizamos las vitaminas, vemos que hay sólo una, el ácido pantoténico, intimamente relacionado con la pelagra y que su falta da lugat a trastornos psíquicos. En 1938. Spies, Morgan y colaboradores encontraron que su carencia produce en las ratas de pelaje oscuro un aclaramiento del pelo en zonas extensas "anti grey factor", quz no sana si se agrega ácido nicotínico o piridoxina, pero sí cuando se agrega ácido pantoténico. Esto lo denominan acromotriquia, en nuest to casc sería lo contrario, pues el color es al principio oscuro y después con la mejoria del cuadro nutritivo, la punta va aclarando.

He creido que la hiperqueratosis va relacionada con la avitaminosis $\AA$. Hay veces en que no existe gran hipetpigmentación y tenemos sólo el cuadro de hiperqueratosis y edemas aunado a otros síntomas como falta de lágrimas, sequedad de la conjuntiva y la anamnesis revela la falta completa de grasas en la alimentación. Por lo demás, esta hiperqueratosis ha sido descrita como avitaminosis A. ya que esta vitamina tiene el rol de ser protectora del epitelio, tal como lo sostienen autores como Rappaport, Stricbe, etc. Hallidey ha creido que dermatitis con biperqueratosis son debidas a la avitaminosis B6 (piridoxina), la misma que Giorgi denominó antiacrodínica, en relación con una defíciencia de ácidos grasos en la alimentación.

El punto ha sido sorprendentemente ilustrado al descubrirse el ácido linoleico, que tiene una acción 'curativa de las dos alteraciones cutáneas en los animales, el tipo acrodínico por carencia de B6 y la dermatitis con hiperqueratosis y caida del pelo por la insuficiencia en la administración de ácidos grasos. Una pequeñísima cantidad de ester etil linoleico, 10 mlgrs. por día, restablece la normalidad. Schneider, en 1940, encontró que la dermatitis de los ratones obtenida por la deficiencia de vitamina $B 6$, puede curarse solamente con la administración de ácidos grasos no saturados naturales; tam. bién obtierien el mismo resultado Salmon, Lunde y Kring stadt. 
Tenemos aquí el problema de determinar si esa hiperqueratosis es producida simplemente por una pelagra, por una avitaminosis $A$, por una avitaminosis $C$, por una avitaminosis B6 o ácidos grasos. Creemos sumamente difícil concurrir hasta ahora al esclarecimiento completo sobre la, materia. Sólo podemos decir que con una alimentación completa sana rápidamente.

Prurito e hiperexudación.-Recalca el frecuente rasquido del niño en zonas como la cara exterra del brazo y la parte pigmentada de la base del cuello. Semejan aquellos macacos del jardín zoológico que están frecuentemente rasgunando su piel. El prurito es en consecuericia manifiesto $y$ sobre todo en las regiones antedichas.

$\mathrm{He}$ hecho notar anteriormente el signo de la linea blanca que puede observar personalmente en muchos de estos niños: después del rasquido superficial y suave de la piel per. dura esa línea blanca por un tiempo mayor de dos, cuatro, basta 12 y 14 horas, según el grado de la hiperqueratosis.

A este sintoma de la línea blanca le sigue otro de mayor interés y que he observado con detención. En aquella región de la parte posterior del tórax cerca de la raiz del cue1lo, en el abdomen y en la parte anteroexterna del brazo, ese rasquido superficial aparece al día siguiente, sin que se apre. cie en el momento de efectuarlo la menor exudación, una línea costrosa, característica: esto es lo que denomino el signo del rasquido, típico y característico de nuestros cuadros carenciales que revela fuera de la hiperqueratosis una hiperexudación de la piel. El examen histopatológico demuestra la hiperqueratosis, la atrofia de la zona malpighiana, la hiperpigmentación y la infiltración del corion con histiocitos $e$ in filtraciones linfocitarias alrededor de los vasos. Esta exudación del corion con atrofia de la piel correspondiente es la que explica este signo del rasquido que hasta ahora he sido el primero en describir.

Organo de los sentidos.-Ojes: Es el ojo uno de los ór ganos que refleja cuadros de avitaminosis como de deshidratación. En nuestros enfermos lo que resalta es la ligera conlgestión de la conjuntiva y el espesor de ella. Si se bace dirigir la vista del niño a uno u otro sentido llama la atención el plegamiento de la conjuntiva con ondulaciones tales como. las olas del mar. Cuando hay edema, éste se refleja en las conjuntivas, notándose que aquella parte del ojo en donde se retrae aflora pot el edema correspondiente. Llama la atención que llorando el niño no tiene lágrimas, debido, proba- 
blemente a una cornificación de las células de las glándulas lacrimales. Si con una cucharilla se hace un raspaje de la conjuntiva y de la córnea se encuentran células epitelialés, escamosas, estratificadas y queratizinadas; esta tinción debe hacerse con violeta de genciana por dos minutos y descoloreada con alcohol-ácido. Las células epiteliales degeneradas retienen la violeta de genciana mientras que las otras se descoloran; las células queratinizadas completamente ro tienen núcleos y se coloran intensamente. La avitaminosis $A$ se diagnostica encontrando lo menos una o dos de estas células con campo de potencia baja. También de la tráquea, de la nariz y de la orina pueden sacarse estas mismas conclusiones.

Al mirar de soslayo la conjuntiva puede llamar la atención la sequedad de ellas y como ya dije, la irregularidad en su superficie (xeroftalmia). Las manchas de Bitot propias del cuadro de la avitaminosis A no las he observado sino en ocho ocasiones. Estas representan en la parte externa de la cnnjuntiva unas pequeñas manchas blanco-amarillentas que afloran de la superficie conjuntival. Unos las han comparado a espuma: las que yo he visto no aceptan tal comparación, sino que como trozos pequeños de barquillo sobre la superficie. Ceden rápidamente a la suministración de vitamina $A$.

La queratomalacia esencial es sumamente rara: sólo en tres casos los síntomas de ésta los he considerado patognomónicos. El rápido enturbiamiento de la córnea se hace por horas sin que la superficie se torne muy seca sino que cuando la cpacidad de la córnea es completa. En el tipo de queratomatacia esencial. a diferencia de la secundaria por deshidratación $e$ infección. $1 a$ inyección conjuntival es mucho menos intensa. ligera congestión acompañante de la xeroftalmia. En la queratomalacia secundaria la ulceración corneal es lo precoz, mientras que en la esencial se efectúa al final previaTiente a la panoftalmitis.

La relación de la formación del púrpura visual y vitamina A es de todos conocida. La hemeralopía que representa síntomas por falta de regeneración dol púrpura visual en los conos y bastoncitos retinales es un síntoma observado en el adulto, pero de muy difícil interpretación, o mejor dicho, de errónea interpretación para certificar la avitaminosis $A$. El test fotométrico en el estudio de la hipovitaminosis $A$ es altamente criticado y asi Tisdall, J. Mc. Creary en el Practice of Pediatrics de Brennemann dicen lo siguiente: Personas normales no se dan cuenta de la difícultad de readaptación de la 
visión después de estar en la oscuriład. Muchos instrumentos har sido preconizados para este objeto. El principio de la mayoria de ellos es de un fotómetro para medir la sensibilidad del paciente a la luz después de un periodo de adaptación a la oscuridad. Tales pruebas han dado resultados muy perturbadores en los cuales los investigadores han encontrado el 20 a $60 \%$ de la gente de ser deficiente en vitamina $A$. Trabajos recientes han mostrado una falta completa de correlación entre los resultados de tales pruebas y las medidas de vitamina en la sangre por el método del tricloruro da antimonio. En el niño, a lo menos en que hay un factor de pobre cooperación, estos medios de probar la eficiencia de ritamina $\bar{A}$ no han sido todavía adecuados.

El que escribe $y$ que ha visto innumerables casos de xeroftalmias y avitaminosis A con hiperqueratosis de la picl y con determinación de la vitamina A en la sangre por el tricloruro de antimonio en 30 casos con unidades amarillas Lovibond y unidades azules Lovibond, por debajo de 1 , siendo lo normal alrededor de 6 en ayunas (Dr. Eduardo Agrela Giemza) no ha encontrado nunca un caso claro de hemeralopia. Ha ido especialmente en las tardes a observar a estos lactantes y niños en cuartos sombreados, sin que haya netado ninguna diferencia con los normales.

De parte del rinofarinx, del cual se puede con una tótula y un espéculum sacar las células superficiales y demostrar su hiperqueratosis en la avitaminosis $A$. no hay sintoma espucial, sino las frecuentes rinofaringitis y bronquitis oluservadas en estos cuadros.

De la laringe llama la atención la voz un poco ronca quz demuestra, o una laringitis catarral, o como dicen otros. una disfonía por una queratosis del epitelio de las cuerdas vecales.

Las complicacicnes bronconzumónicas son la regla en Jos casos avanzados y la anatomía patológica refleja un tipo de bionconeumonia paravertebral o bronconeumonias abseedentes o abscesos banales. Más raro es observar neumonias.

Aparato urinario. Schittenhelm al describir el síndrome edema en el libro de Stepp y Giorgy sobre Avitaminosis, llama la atención sobre la poliuria y polaquiuria como sintomas acompañantes. En nuestros casos, en un principio hay por el contrario, una disminución de la orina, un aumento de su peso específico, condensaciones de uratos y una piuria. La hemos interpretado como una forma de piuria por deshidratación (Schiff) porque luego de fundidos los 
edemas y alimentado el niño, esta piuria desaparece. Pero no todos los casos se presentan en esa forma, sino que fuera de los elementos antedichos, encontrados en la orina, hay albú. mina por encima de 0,30 a 0,40 gramos por mil, glóbulos rojos y cilindros. Esto habla en favor de un tipo de verdidera nefritis, espejo de la infección circulante, ya sea la enterocolitis, septicemia, tuberculosis, etc, que es la base del cuadro clínico.

Extraña sobremanera la relación que hay en todos estos casos de síndromes carenciales con o sin edemas, en la palpación de ambos riñones. Esta nefromegalia no está en relación con los hallazgos urinarios pues purede presentarse cuando hay una albuminosis, una hematuria y cilindrutia. conı cuando hay sólo células epiteliales, piuria y concentración urinaria. La relaciono con este cuadro de síndrome carencial. con una avitaminosis y probablemente con la avilaminosis $A$. Eso sí hay que llamar la atención que la calculosis en nuestro medio infantil, a pesar de la alimentación tan pobre en grasas, no se presenta con frecuencia, por el contraric, es una rareza. Otra explicación es que también el riñón puede tener en estos casos relación como órgano de secreción interna y aumentar de volumen como medio de estimulación por la falta de elementos esenciales que se ofrendan a estos riños. $Y$ por último, son las causas más frecuentes de este aumento de volumen las nefritis intersticiales, como así también las malformaciones congénitas de las vias urinatias y las retenciones urinarias consiguientes con infecciones y alteraciones del parenquima, que sólo en muy raras ocasiones va accmpañada de insuficiencia renal. Esta insuficiencia renal como cierto tipo de nefritis intersticial y nefrosis están en relación con el crecimiento y desencadenamiento de ciertas avitaminosis como be podido ver en un caso de pelagra, o de raquitismo renal, raquitismo osteomalácico o de tetania. $O$ sea: en otros términos, que por alteraciones en el aparato exctetor. pueden condicionarse ciertas avitaminosis como: el raquitismo, tetania, pelagra, etc.

Aparato genital._-En las niñitas se presenta con freçuencia una vulvovaginitis catarral que sana rápidamente con la mejoría del cuadro deficitario.

Aparato circulatorio. Trastornos vasomotores. - Sun éstos los que presiden, puede decirse, la sintomatología de parte del aparato circulatorio. Al iniciarse estos sindromes carenciales hay una transpiración helada en la planta de los pies y palma de las manos, con coloración rosada-violácea y 
violácea especialmente en períodos de frío. Este trastorno de dilatación capilar se puede observar también en el vientre alrededor de la región umbilical. Se dibuja a través de la piel y en los sectores correspondientes a las portas accesorias una dilatación venosa, que asemeja a un naevi, tomando aspecto como punto hemorrágico y en seguida sobre esta superficie viene una hiperpigmentación y descamación. Lo mismo accritece en las manos y pies. Parece tratarse como una verdadera parálisis vasomotora con infiltración pericapilar. a la que luego se agregan pequeñas hemorragias y trombosis de las pequeñas venas, como explica White y Hadfield en la pelagrá, $y$ en seguida los trastornos de la piel de biperqueratosis e hiperpigmentación.

Lo que resalta en estos tipos de niños es la visibilidad de las venas ingurgitadas y visibles a través de la piel en el dorso de las manos, en los brazos y aún en el abdomen $y$ tórax.

Las presiones venosas hechas en niños mayores de un año y con la paciencia consiguiente de esperar que terminen de llorar, y en los mayores de tres años, los cuales prestan cooperación durante la prueba, demuestran que son muy altas. Esto explica patcialmente la formación del edema en las partes más distantes de la economía no existiendo ninguna lesión cardiaca: se ha buscado con esmero en los casos anatomopatológicos el corazón beri-beri con el aumento del ventriculo derecho y el edema interfibrilar y no lo hemos encontrado en ningún caso. Hay, pues, en este mecanismo de Ja dilatación venosa, aumento de la presión y dilataciones $e$ infiltraciones alrededor de los capilares venosos en la piel, un factor probablemente inervioso, reurovegetativo, que tiene como sabemos además, una acción sobre la formación de pig. nentos en la piel. Esto también serviría de explicación en la localización de los edemas tar perfectamente bien limitados en bota o manguito, tal como lc hemos descrito anteriormente.

I.as alteraciones vasomotoras pueden también probarse por los fenómenos de intenso dolor que se provoca con la compresiór venosa del brazo y los daños que pueden llegar hasta la gangrena por cambios bruscos de temperatura, como por ejemplo un caso de gangrena del pie por exposición al frío después de un sobre calentamiento en el brasero (caso clínico).

Sangre.-En el examen de la sangre de estos enfermos, llama la atención la cantidad de glóbulos rojos que fluctúa 
entre 3 a 5 millones y los glóbulos blancos por encima de 10,000. La leucocitosis es explicable por las infecciōnes securdarias y que va además aunada a una desviación a la izquietda, pero, en niños con este déficit alimenticio, extraña esta cantidad de glóbulos rojos. Una vez fundidos los edemas, la cifra de glóbulos rojos generalmente cae, indicándo. se un aumento de la viscosidad sanguínea o exicosis que luego después se mejora con la disminución de la cifra de glóbulos. La hemoglobina, está también en un principio en la mayoria de los casos alta, manteniendo un valor globular cerca de uno. El recuento y fórmula no nos da ninguna luz sobre el particular. Hay algunos que presentan una vez combatida la exicosis una anemia de tipo megalocítico y que, las inyecciones de extracto hepático total o Beanemol dan lugar a una curva ascendente que indica en forma ostensible su acción. Probablemente se trata de anemias de tipo avitaminósico por falta del factor externo o interno del complejo vitamínico B. A pesar de ello, la administración de levadura por vía oral no ha dado el resultado que se esperaba, ni tamproco el ácido nicotínico, ni la vitamina C ni B.

La mayor parte de las colestetinemias y glicemias efectuados en el servicio nos dan cifras bajas, entre 0,70 y 0.80 gramos por mil. Glicemias hechas en el momento de la hospitalización y después de tres a seis días en que el edema se ha fundido, demuestren lo mismo que se ha hablado con respecto a los glóbulos rojos, que la cifra al iniciatse es de alrededor de 1 en ayunas y después baja a 0,70 ; esta hipoglicemia va acompañada a veces de fenómenos acidóticos que se manifiestan con la respiración cánsada, olor a manzana y la disminución de la reserva alcalina. Es ese el momento más peligroso de estos cuadros, en que fumden con rapidez sus edemas y se ha iniciado la alimentación a base de leche albuminosa: gran parte de esos niños fallecen en ese período, no encontrándose en la autopsia siro sintomas de degenera. ción gránulo-grasosa del hígado.

Aparato digestivo.-Los síntomas subjetivos que presentan la mayoria de estos niños son en primer término, los vómitos y en segundo término, diarreas. El vómito puede ser un vómito neuropático, vómito forzado por el mismo niño como un međio defensivo de rechazo a una alimentaciön que él no desea o no le guste. En otras ocasiones es un vómito por atonia gástrica en qua a la pantalla fluoroscópica se encuentran restos alimenticios después de cuatro horas y falta de contracciones peristálticas francas. Otras veces es una 
verdadeza gastritis por irritación de la mucosa por ingestión de alimentos y aún hasta alcohol o vino. El rexamen del jugo gástrico revela en los casos que hasta abora hemos estudiado una falta de ácido clorhidrico libre: esperamos hacer un trabajo más completo sobre la materia para ilustrar en el futuro sobre el particular.

Ya hemos hablado sobre el apetito caprichoso y la anorexia intensa que a veces es necesario combatir.

La boca presenta características interesantes. Se puede presentar un aumento de los capilares en la mucosa bucal, sobre todo muy notable en el ángulo o repliegue entre la mucosa del labio inferior $v$ el maxilar. Estos capilares se aprecian ingurgitados $\mathrm{y}$ a veces de un color cianótico o rosa cianótico peculiar. Antes de llegar a la encía, cuando se estiza el labio, este acto trae como consecuencia la compresión de los capilares con la formación de una franja blanca. Por debajo de ella en algunos casos se forma una pigmentación perfectamente bien limitada y paralela al reborde gingival. No sé si esto es escorbútico o pelagroso o no tiene ninguna innportancia. En otros casos se encuentra la mucosa bucal enru. jecida especialmente al nivel del paladar óseo en la parte media, acompañada o no de algorra; en otros, ulceraciones especialmente en la mejilla, que molestan at enfermito y que le ocasionan picazón o ardor. No he observado síntomas de perturbaciones de sabor, como el ardor salado de la pelagra. Respecto a la lengua, ésta a veces tiene unia saburra espesa, color café oscuro en la base y que llega hasta cerca de la punta. dejando parte de ella libre y con las vellosidades marcadas. En ottos casos se encuentra una lengua depapilada con ulceraciones resquebrajadas en los bordes que es la típica descrita para el Sprue o diarrea de la Cochinchina. Otras veces representa la lengua de la pelagra, con la desaparición en la punta de las vellosidades papilares y dejando las vellosidades fungiformes, y en otras encontramos la glositis de Hunter o la lengua geográfica.

La lengua de la pelagra anteriormente descrita, ha sido observada típicamente en niños con pelagra en período escolar y este sintoma tal como la dermatosis y la melanodermia perfectamente bien demarcada y con toda la sintomatología propia a este cuadro, cambia de un dia para otro, observándose saburra y descamación de la lengua en forma alcernante e irregular.

El examen del vientre, presenta diferencias en estos cuadros, en unos es globuloso protuberante. pseudo ascítico, 
en el cual aun se puede dibujar las venas portas accesorias, las epigástricas, etc. Este vientre balonado va acompañado también de un intenso glou-glou a la auscultación del estetoscopio. Además, el examen radioscópico revela en muchos de ellos un dólicocolon especialmente sigmoídeo (signo de Bernedetti en infantilismo intestinal) y varios nivales liquidos en las asas intestinales. Estos tipos de abdómenes voluminosos van acompañados además de deposiciones con grasas neutras y ácidos grasos, deposiciones de gran volumen y con un peso mayor de 120 a 150 gramos. Son deposiciones de color blanquizco grisáceo, de olor ácido, espumosăs, con gases, semisólidas que imitan a las de la enfermedad Sprue y otras como puré de nueces a imitación de la deposición acrodínica.

En otros, el vientre es normal, no se aprecia aumento de volumen, pero puede presentar también el mismo tipo de deposiciones descrito anteriormente, aunque es más rato. A veces se palpan masas ganglionares en la fosa ilíaca derecha con reacción dolorosa espontánea y provocada. Eso habla muy en favor de una tuberculosis mesentérica.

El hígado en estos síndromes carenciales su observación continuada y acuciosa tiene una importancia enorme. El sindrome carencial con edemas y una hepatomegalia, es signo inequívoco de que hay una alteración profunda en este órgano y que al cuadro lo acompaña una infección grave, una septicemia, septicopiohemia, tuberculosis, tifoidea, paratifus, neumonia, bronconeumonia, enterocolitis disentérica, de curso subagudo y crónico. Pues, en la distrofia carencial con edenas, el hígado parece que tiene una relación íntima con la imbibición acuosa en los tejidos y así se explica que este órgano se esconda dabajo del reborde costal en el período álgido del edema y que a medida que esta imbibición extracelular de agua va eliminándose y se: va alimentando mejor el enfermo, el hígado aumenta a parejas con esta mejoría y con el aprovechamiento del alimento ofrendado. En casos de degeneración del hígado y atrofia de éste, el hígado no aumenta y se mantiene tal como el primer día. lo mismo pasa con el hígado en un estado caquéctico.

El bazo aumenta de volumen en presencia de una infección septicémica como la fiebre tifoidea y tubertulosis, pero en el cuadro único carencial, éste está retraído y escondido como el hígado.

Diarrea.-En la mayoría de estos enfermos tenemos una diatrea con deposiciones con mucosidades, pus y algunas otras 
veces sangre fresca. Es necesaric para interpretar la diarrea reconocer si hay o no un prolapso rextal, síntoma que con relativa frecuencia acompaña a estos cuadros: estas diarteas son a veces postprandiales, de color verde, otras veces amarillentas, con reacción casi siempre alcalina. Sometiéndolos a la alimentación a bisc de leche albuminosa y de verduras, legumbres, carnes $y$ frutas, otservamos estas deposiciones grisáceas a que se ha hecho alusión de olor a mantequilla rancia y que conteine gran cantidad de restos grasos. ácidos grasos y jabones. Este tipo de deposición demora algún tiempo en mejorarse a pesar de la dieta rica en albúminas, relativamente pohre en grasas y de distintos tipos de hidratos de car. bono y gran cantidad de vitaminas. Observados estos niños en estos períodos hace formular el diagnóstico de enfermedad de Herter-Heubner o enfermedad celiaca o infantilismo intes. tinal, o si se encontrara en los trópicos enfermedad de. Sprue o diarrea de Cochinchina, pues la lengua depapilada a veces $y$ ulceraciones de la boca y lengua, como así requebrajaduras cerca de la punta, son elementos suficientes para formular ere diagnóstico. Acompañante a estos cuadros, puede existir o no una anemia, una ligera leucocitosis, pero no una eosinofilia manifiesta.

Estas diarreas pueden ser también originadas por una enterocolitis crónica. tipo Flexner, en que los agentes quedan englobados en forma de quiste en los folículos cerrados y despiertan en su actividad en forma intercurrente. Ottas veces la amebiasis puede presentar un mismo curso crónico.

Hay también aquí un maridaje de estos cuadros carenciales con una parasitosis intestinal. Indudablemente que así como Sprue y pelagra y ciertas infecciones en el niño preparan el terreno en el tubo gastrointestinal para que se generen hongos y otros como el oidium albicans, así también los parásitos intestinales encuentran terreno abonado para asentar su residencia y multiplicarse en rápida proporción en el tubo gastrointestinal del niño carencial. Es así cómo encontramos en la fiebre tifoidea de larga duración, en la meningitis tuberculosa y en otras, el áscaris lumbricoides como huésped casi obligado. En estas distrofias carenciales, a veces es tal el número de ellos que se dibujan los movimientos ventriculares a través de la pared abdominal. Cuando el niño está tranquilo y su pared abdominal relajada, tomando con la mano parte de la pared abdominal con intestino, puede sentirse cntre los dedos las masas de áscaris que se escurren entre los pulpejos. Las deposiciones tienen a consecuencia de ello un 
olor típico cuando bay muchos áscaris, que yo lo comparo al olor que sale de un hueso cuando se raspa con la rugina. los áscaris se eliminan solos en gran número de casos sin necesidad de antihelmínticos, a medida que el estado general mejora, que la allimentación es completa y que el peso aumenta. Otras veces el áscaris muerto en el intestino provoca grandes síntomas de intoxicación que puede acartear lá muerte precedida de convulsiones. Además, las larvas en gran cantidad en la sangre pueden ocasionar la muerte por bronconet!monia.

La lambliasis es otro de los parasitismos frecuentes en estos tipos y su presencia puede ocasionar diarreas intercurrentes que no sanan si no se someten al tratamiento de los arsenicales.

Las tricomonas, botriocéfalus latus y el tricocéfalos dispar juegan un rol muy secundario en estos síndromes clínicos.

La tuberculosis es la enfermedad que promueve mayor pleomorfismo en su sintomatología, pero hay un hecho bien visible y es que la adenopatía traqueobrónquica no influye en la tuberculosis en su estado nutritivo; mientras que la tuberculosis mesentérica aflora una facie vultuosa, una piel seca, queratótica y tendencia al edema. Son numerosos los cuadros carenciales cuya causa reside en una tuberculosis mesentérica, peritonitis tuberculosa y lesiones hepáticas del misno origen. Es comprensible que en estos casos haya un balance negativo de grasas y ácidos grasos que no son absorbidos por los quiliferos enfermos. Así también ese hígado lesionado por la noxa tuberculosa y por las localizaciones miliates de ese órgano está incapacitado en parte para el metabolismo y síntesis de algunas sustancias elementales para la nutrición. En el diagnóstico es importante el observar la hepatomegalia en estos síndromes carenciales con edemas, pues indica la mayoría de las veces una tuberculosis. La palpación profunda de la fosa ilíaca derecha, revela masas ganglionates tuberculesas. También hemos encontrado una relación. en niños mayores, de pelagra y tuberrulosis de los ganglios mesentéricos y alteraciones hepáticas. En tres niñitas del ser" vicio de segunda infancia hubo esta asociación: pelagra y tuberculosis mesentérica.

\section{Avitaminosis ostensibles en relación con edtos cuadros}

Raquitismo.-En muchos de estos niños encontramos cuadros de raquitismo franco, lesiones principalmente circunscritas a las extremidades y tórax. 
En la cabeza podemos encontrar restos de un raquitismo c las protuberancias parietales, frontales y defectos del paladar y dentición; pero la hipotonía, abultamiento de las epífisis. deformitades del tórax, raquis, y el examen de la sarigre que revela una hipocalcemia e hipofosfemia, está ratificando este cuadro avitaminósico. En la radiografía no encontramos en la mayoría de los casos, signos inequívocos de este mal, sino una osteoporosis que semeja el thueso como en el escorbuto y que los americanos han denominado como tipo de hueso parecido al vidrio empavonado.

En el período de convalecencia y mejoría de estos síndromes, sí que aparece raquitismo, o más bien dicho. la perturbación metabólica calcio y fósforo, exteriorizándose como una tetania o espasmofilia y catatonia. En otros hay lesienes francas clínicas y radiográficas.

Avitamincsis $\mathbf{A}$ - - Hemos hablado anteriormente de la xeroftalmia, manchas de Bitot y queratomalaria. Atribuímos la hiperqueratosis en algunos de estos cuadros a la avitaminosis $A$, pero pata ello hubimos de recurrir al examen de $1_{d}$ sangro con tricloruro de antimonio al $30 \%$ y así el Dr. Agrela, de nuestro servicio, en 73 observaciones y determinaciones por medio de la R. de Carr y Price pudo comprobar que en nuestras distrofias carenciales existía una cantidad de unidades amarillas entre 2 y 3 . (normal de 8,6 unidades) y unidades azules entre 0.9 a 1.1 (normal 1.4 por $10 \mathrm{cms}$. de suero). Blackfan en la A. M. J. of D. of Ch. publica dosís un poco mayores.

A pesar de esta dosis tan exigua en la sangre no presentaban hemeralopia, ni queratomalacia, sino que exclusivamente la hiperqueratosis y la xeroftalmia y engrosamiento de la conjuntiva.

Avitaminosis C.-Escorbuto clásico o enfermedad de Moller Barlow es relativamente rara observarla. Mucho más frecuente, estados subclínicos que no pueden diagnosticarse sino por medio de la prueba de la saturación de la vitamina C. a ácido ascórbico en la sangre y orina. No sirve para el diagnóstico la simple determinakión del ácido ascórbico o ácido cevitámico tanto en la sangre como en la orína. Los trabajos hechos en la clínica por los. Drs. Brücher y Julio Salinas y Gallinato nos demostraron el error que representaba el formular diagnósticos al encontrar dosis en la sangre menores de $0.60 \mathrm{mgrs}$, por ciento y la eliminación por la orina de dosis pequeñas de esta vitamina. Más tarde Fernández Ferrufino en la Casa Nacional del Niño llega a la misma 
conclusión. Recordemos nuevamente el experimento humano hecho por un estudiante de medicina de Boston, el cual pasó curante un período de 6 meses sin ingerir ácido ascórbico: a los 132 días aparecen pápulas hiperqueratóticas y a los 161 dias las hemorragias perifoliculares, pero el nivel de! ácido ascórbico en el plasma llegó a 0 trece semanas antes de los primeros signos clínicos: en consecuencia, no es un buen indicio esta determinación para poder formular diagnósticos. Mucho más importante es el nivel vitamínico en la capa blanca de células trombocitos, éste cayó a 0 inmediatamente an tes de la aparición del escorbuto clínico. De mayor interés e impottancia es la prueba de saturación que demanda algún trabajo y molestia. Se necesita previamente que sea un varón que esté sometido a la misma alimentación anterior, sin nigún agregado de vitamina $C$ y en seguida se determina en la orina la cantidad de esta vitamina, después de algunos días se inyecta $1.00 \mathrm{mgts}$. de ácido ascórbico diariamente intramuscular y se toma la cantidad de orina total de 24 horas. En esa forma se ve si el organismo elimina dentro de las primeras cuatro horas parte de la cantidad inyactada. Cuando hay escorbuto la eliminación se hace después de unos 6 a 8 días. indicando que esta vitamina ha sido aprovechada primeto en los tejidos $y$ ha demorado en saturar al organismo más de 24 horas que sería el tiempo aproximado de una persona normal. Hay que insistir que esta prueba de nada vale si no se toma la orina de 24 horas, por lo cual es molestia para el niño y para la enfermera la colección de esta excreción.

Las pruebas de la fragilidad capilar como la de Gothlin. Dalldorf y la de Rumpel Leede no son de la precisión y fineza que se creía. Hay casos de escorbuto franco con Rumpel Leede negativo y además, esta fragilidad puede variar en distintos puntos del organismo. Son pruebas en consecuencia. bastante pobres y no precisas para el diagnóstico de avitaminosis $C$ clínico y subclínico.

Avitaminosis B1.-Es de pensar que con la alimentación deficitaria y recalentada de cereales camo es la de nuestro pueblo, el aporte vitamínico B1 o cloruro de thiamina que es termolábil, se destruye. Sin embargo, no se nos pre. senta la avitaminosis beri-beri. Es conocida además la relación entre alimento hidrocarbonado y esta vitamina, pues sólo se presentan los cuadros avitaminósicos con una alimentación excesiva de hidratos de carbono o alcohol. También la grasa junto al hidrato de carbono puede tender a la misma acción. Los reflejos débiles en algunos tipos de niños caren- 
ciados con edemas los atribuyo más a orden mecánico, porque luego desaparecidos éstos, los reflejos son por el contrario, vivos. La dilatación del ventrículo derecho, el ederna del miccardio e insuficiencia aguda cardíaca mortal, como se describen en lactantes hijos de madres con beri-beri, no los he cbservado nunca. Sólo un caso de insuficiencia cardíaca aguda fué ocasionada en uno de estos enfermitos por la anasarca y el gran edema. El aumento de la presión venosa que también podría ser achacada a un trastorno de insuficiencia circulatoria derecha, no lo es por las razones antes expuestas y creo, se trata de fenómenos neuromotores de origen central. En consecuencia, no creo que nuestros casos sean de beri-beri. Hay sí, una avitaminosis subclínica que seguramente está en relación con el metabolismo hidrocarbonado y quién sabe si con el metabolismo acuoso. Es bajo este punto de vista que podemos interpretar nuestros cuadros clínicos carenciales.

Arriboflavinosis. - La vitamina B2 identificada como fermento amarillo de Warburg tiene, como se sabe, la función del fermento de la oxidación de los tejidos. En caso que este no exista en sitios donde no hay irrigación sanguínea se produce falta de respiración del tejido e inflamación con neoformación de capilares. Así, en la córnea en la arriboflavinosis, se produce congestión en el limbo corneal y una opacidad corneal. La cara se torna rosada, telengectásica, hay una queilosis que consiste en fisuras y ulceraciones especialmente en las comisuras bucal con poca tendencia a la curación; también se produce ún acné cutáneo rosáceo y acné rulgares, lo mismo que una dermatitis seborreica.

Estos síntomas no los hemos encontrado en forma clara. La rubicundez de la cara, la inyección conjuntival y limbo corneal, la querlosis, ban sido registradas en un número restringido de casos.

Pelagra y Sprue.-Es indudable que es ésta la afección más frecuente en nuestro grupo. Su aparición con el cortzjo sintomático clásico, se observa en pocos niños y siempre en mayores de 2 a 3 años. Las alteraciones del psiquis, la anorexia. los fenómenos intestinales, la hipoclorbidria, los reflejos aumentados, la ánemia ligera y las típicas demostraciones de la piel. dermatosis, melanodermia demarcada y simétrica en regiones clásicas: dorso de las manos, hasta antebrazos, demarcación nítida con aumento de la pigmentación a ese punto, dorso de los pies hasta la región del tarso, cuello de Casal, formas amatiposadas en la cara, extensión esternal y hacia la región de las apófisis espinosas. Descamación que 
deja siempre en el límite una mayor pigmentación. Ligero prurito, parestesias. El examen histopatológico, aunque no formula un diagnóstico de precisión, puede, junto al examen clínico, servir para afianzar el diagnóstico. Este examen da hiperqueratosis, paraqueratosis, atrofia de la piel, melanosis visible con las coloraciones corrientes en el estrato malpigiatio; si ya hay una evolución más crónica, atrofia papilar, infiltraciones del corion, desaparición de las fibras elásticas y colágenas e infiltraciones de células redondas alrededor de los vasos. Estos hallazgos microscópicos difieren mucho en el nomento en que se verifiquen; periodos de la dermatitis, de la melanodermia, de la descamación. del período crónico o caquéctico. Las zonas de vitiligo o leucodermia o hipocromia observables en estos casos, son también según Merck y Jadassohn. propias de la pelagra. Sin embargo, hay otros que citan la melanosis del vagabundo, en el cual la pediculosis, $J$ sarna o impétigo, pueden dar lugar a las mismas zonas des. ccloradas dentro de la coloración oscura cutánea.

Las manifestaciones en la lengua son también típicas, pero no persistentes. Esa lengua depapilada y rosa-violácea puede observarse en ciertos momentos del enfermo. A esto se agrega como en el Sprue ulceraciones de la mucosa bucal y requebrajaduras del borde de la lengua que provocan dolor o molestias al tragar. El gusto salado propio de la palagra que anuncian estos enfermos, no me ha sido posible encontrar.

Las deposiciones tienen las características que se han ci.tado para los trastornos gastrointestinales de estos síndromes carenciales. Anorexia, vómitos, diatreas en número de 4 a 5 - más, deposiciones abundantes, grisáceas, espumosas, algunas de consistencia clara o semisólida. otras más espesas. El peso de ellas es alto y conteniendo grasas, ácidos grasos y jabones. El vientre balonado, pseudo ascítico, representa aquellos casos descritos de pelagra y Sprue asociados.

El ácido nicotínico instituído en estos chicos en dosis de 100 a 200 mgrs. no impresiona tanto en su efecto, como los resuitados o mejorías obtenidos con alimentación completa a base de albúminas, grasas e hidratos de carbonos que se ins. tituyen.

Las transfusiones sanguíneas tienen un efecto mucho más scrprendente que cualquiera otra medicación. Estas dan aún mejor resultado si se saca la sangre a la media o una hora después de haber alimentado al donante con bastante albúmina y grasa animal. 
Edema carencial.--Estos son perfectamente localizados $y$ especialmente en las extremidades inferiores. Podemos $\mathrm{d} z$ cir a medida de comparación que son edemas en bota y manguito. Si la afección deficitaria continúa, el edema sigue hasta el vientre, las extremidades superiores hasta los hombros y en la cara éste se hace manifiesto especialmente en los párpados. Queda libre en un principio el tórax en su parte alta. apariencia que contrasta fuertemente del resto del cuerpo. Si el estado de carencia o hambre continúa, se transforma en una anasarca, presentándose en consecuencia el edema generalizado y el transudado en las cavidades serosas. Hay épocas del año en que el síntoma es más frecuente y así tal como lo describe Schittenhelm, en el libro de Avitaminosis de Giorgy, aparece en el otoño e invierno, o sea, en telación con el frío. $\mathrm{Si}$.se observa la curva de morbilidad de estos síndromes 11 a. ma la atención que es en Marzo donde hay una alza brusca. Esto tambièn está en relación con la iniciación del frío invernal. Precediendo el edema hay síntomas como enfriamiento, transpitación helada, color rosado o rosa-amoratado, como telatigectásico. En niños mayores se les puede sonsacar algunas perturbaciones sensitivas como hormigueo, parestesia, sensación de frío. Luego después aparece el edema en forma insensible en las piernas, demostrándose pesadez. cansancio. deseo de mantenerse en un estatismo casi completo. Si viene una infección, el edema se puede iniciar bruscamente, tal cono si fuera inflamación renal. Siempre el edema es mucho más notorio en las extremidades inferiores y bien demarcado. La presión venosa demuestra siempre un aumento en los momentos de generarse el edema sin que exista ningún sintoma de insuficiencia ventricular derecha, no hay hepato ni esplenomegalia, ni oliguria. Estos fenómenos deben ser generados por un trastorno vasomotor dirigido lo más posible por el sistema nervioso central; en la misma forma de aquellos edemas que se producen en caso de hemiplegia. Junto a eso tenemos la predisposición a la extra-vasación de líquidos en los tejidos por la gran hipoproteinemia como asi la retención de sal o cloruro de sodio en los tejidos por la gran oferta de ésta en la alimentación. Otra razón para la gestación de este edema debe buscarse en el estado de los capilares y de las substancias intercelulares de las paredes del endotelio, las cuales están segu. amente comprometidas o afectadas por la sub avitaminosis clírica que estos cuadros nos presentan. Hay en consecuencia trastornos neuro vosomotores y de las paredes de los capila- 
res arteriales y venosos, aumento de la presión venosa, hipoproteinemia, retención clorada. La interpretación de la localización del edema debe buscarse no en la hipoproteinemia ni en la retención clorada porque si así lo fuera, sería éste generalizado tal como en la nefrosis. Estos factores son favorecedores indudablemente pero es el factor frío, neuro vasomotor, aumento de la presión venosa y alteraciones de las paredes de los vasos, los que acondicionan el edema en bota y manguito.

Como ya se ha dicho, sobre estas partes hinchadas, edernatosas, la piel o epidermis tiene una coloración más pigmentada aue luego con la distensión del tejido celular se torna más clara, color café claro brillante o como escamas o losanges pigmentadas con bordes blancos, amplios, que hace semejar a la piel de lagarto.

Es interesante seguir a estos enfermos y despistar su proteiremia, Siempre hay una disminución de las proténas totales por debajo de 60 gramos por mil. Fuera de esta dirminución total hay además una alteración en la calidad de ellas. Las serinas bajan de 30 y aun llegan a cifras a la mitad de la anteriot. Las globulinas por el contrario, se mantienen normales o aumentan en el curso de la curación o mejoría de los edemas. Como se comprenderá la relación serinas-globulinas, o sea el cuociente proteico, estará fundamentalmente alterada. Este que normalmente es de 1.2 hasta 2.5 puede llegar a cifras debajo de 0,50. En la evolución es de notar el alza de las globulinas mientras las serinas se mantienen bajas y el ascenso de estas últimas es mucho más lento hasta llegar a la separación completa. Es en este período cuando el cuociente también se torna normal.

Un medio para poder distinguir la imbibición anormal de los tejidos es la hidrofilia. La pápula se producz con 5 décimos de solución de cloruro de sodio fisiológico; tarda en des. aparecer en el niño unos 25 a 40 minutos. En las distrofias carenciales la hidrofilia es un método que prueba la imbibición anormal acuosa del tejiđo celular subcutáneo. La pápula desaparece en algunas ocasiones al corto tiempo de producida y en otras va lentamente desapareciendo y desaparece en casos de edemas ostensibles antes de los 15 minutos. el doctor Fernardo Aguilera, en nuestra clínica hizo una prueba en gran número de níños. Sus resultados son los que acabo de exponer, los mismos que tenemos en los últimos años. Pero hay un hecho importante que merece nuestra atención: los niños 
con síndromes carençiales edematosos, quedan con una perturbación en el metabolismo acuoso, una instabilidad en su curva de peso, una trofolabilidad, o sea especialmente hidrolabilidad. Sus curvas de alzas y bajas de 100, 200 hasta 500 gramos diarios; nos depara estas alteraciones tisulares. $Y$ es la hidrofilia y las proteinas o la calidad de ellas, las que altetan el intercambio especialmente acuoso. Es de hacer notar que los trastornos digestivos, diarreas, deposiciones abundantes y pesadas, pueden influir en este mismo desequilibrio ponderal.

La hidrofilia tiene además otra función que esclarecer. Ella difiere en el sítio en que se haga la pápula. Si se hace en las extremidades inferiores donde existe el edema ya sea ostensible o no, la pápula desaparece con tanta rapidez como se hace en las extremidades superiores, en el dorso de la mano, donde también existen edemas; pero en el tórax, en el vientre, en la espalda y aun en la cara, los minutos de absorción de la pápula son diversos. La explicación de ésto, es que el edema es local, circunscrito especialmente a las extremidades inferiores, a las manos y un poco en la cara.

La hidrolabilidad, la infiltración anormal en el tejido celular y alteración en el tractus intestinal, tiene que estar en relación además de lo ya dicho con las avitaminosis. Conocidas son las alteraciones hidro salinas en el raquitismo o tetania, principalmente el edema en esta última, como así en el escorbuto, beri-beri y pelagra.

Las substancias lipoídeas según algunos, tienen un rol importante en la patogenia de los edemas. Si esto fuera verdadero, podía también la disminución de las lipemias y colesterinemias en nuestros cuadros ya que los valores tanto en liperias como en colesterinemias, hemoconías y unidades Lovibond amarillas y azules son bajas.

Hay frecuentes y recidivas del edema. Puede aún este aumentar si en la alimentación los primeros días damos cloruro de sodio. En consecuencia no debe suministrarse sopas ni caldos con sal ni una alimentación salina. La causa de las recidivas estriba en esto mismo, en que una vez dados de alta, se les da la misma alimentación anterior, hidratos de carbonos y sales, con lo cual la recidiva es casi obligada y así tenemos varias hospitalizaciones con el síndrome carencial con edemas o sino con las perturbaciones gastro intestinales que simula el Sprue o infantilismo intestinal. En otras ocasiones infecciones gripales, parece que desencadenaran de nuevo estos 
cuadros o produjeran grandes bajas de peso con empeoramien. to rápido del estado general, vómitos, diarreas, exicosis, acidosis y muerte con esta sintomatología.

También en el edema tenemos que considerar las lesio. nes renales que acompañan a los síndromes carenciales. Si ya hemos dicho que una piuria por deshidratación es lo corriente, la nefritis intersticial es otra de las complicaciones encontradas. Estas Nefritis intersticiales requieren el tratamiento de transfusiones sanguíneas junto a la sulfanilamida, substancia que ejerce una favorable acción, pero siempre que vaya acompañada de las transfusiones. Se explica el motivo ae esto porque en los sindromes carenciales, la disminución de las. serinas del plasma y el hambre sanguíneo en cuanto a albúminas, grasas y vitaminas es enorme $y$ se requiere combatir las dos cosas a la vez, la carencia y la infección. Si ataca sólo la infección y se da un régimen albuminoídeo con poca sal, puede traer desequilibrios graves metabólicos, una acidosis, etc.

Estas nefritis intersticiales son casi siempre secundarias a las infecciones enterocólicas, tifus, paratifus, tuberculosis o grippe, etc. Y quien sabe si hay además un factor relacionado con la carencia o avitaminosis. Ya hemos dicho la frecuencia de la palpación renal en los cuadros carenciales . Son localizaciones intersticiales. embólicas, que pueden ser de forma embólica miliar hasta la apostematosa. Pero generalmente sanan conjuntamente con el cuadro carencial quedando una hematuria ligeta y piuria que con la mejoría del estado general o reposición completa desaparece.

Cuidado ha de teneres con las nuevas preparaciones en uso como la sulfopiridina, cuya solubilidad en agua es tan escasa. Así pueden formarse verdaderos tapones de cristales de amino-sulfopiridina bloqueando a ciertos cálices renales y produciendo intensos dolores con retención urinaria. A veces estos cristales pueden estar en el comienzo del ureter y dar lugar a una pionefrosis. Esto sirve además de experiencia para suministrar abundante cantidad de agua en estas concreciones de cristales de amino-piridínicos, así como también para no restringir el agua aunque exista este tipo de nef ritis, pues no hay insuficiencia renal, la urea se mantiene en cifras alrededor de 50 centígramos, luego después con la fusión de los edemas y probablemente con la viscosidad sanguinea baja a la normal. Creo que puede existir nna relación entre esta falta de crecimiento del niño con hipotrofia o distrofia carencial y el disturbio renal, alguna función debe ejercer en el ni- 
no la substancia intersticial (hormonal). No en otra forma se explica la relación que con frecuencia se observa en nuestro medio de nefritis intersticiales que no.provocan un'a insuficiencia renal, y una detención y falta de crecimiento.

\section{Antatomía Patológica}

La anatomia patológica referente a estos cuadros carenciales puede decirse que es nula salvo para las infecciones in tercurrentes que son las que producen la muerte. Entre estas figuras las enterocolitis ya en estado de actividad como tipo de enterocolitis folicular o ulcerosa o en regresión o cicatricial. Lo que más se exalta es la adenopatía mesentérica que como ya se ha dicho, es muy frecuente observarla sin que existan lesiones o hayan existido en el intestino. Que razón hay para ello de este infarto, no lo sabemos, ni hasta que punto puede él intervenir para la falta de absorción y aprovechamiento de ciertas grasas. ácidos grasos y vitaminas li. posclubles. E1 hígado es el que con más frecuencia se preserta alterado desde la ligera degeneración gránulo grasosa hasta la generación grasosa completa. Pueden existir además hepatitis con ligera ictericia o tifomas en casos de fiebres tifoídeas.

Disenterías amebianas pueden presentarse pero mucho más raras que del tipo de disenterías bacilares como Flexner por ejemplo. El año pasado era frecuente encontrar tipos de enterocolitis con ulceraciones en las placas de Payer de la última porción del intestino, un poco profundas y reacción peritoneal local y generalizada por este motivo.

Las ascaridiasis también constituye un hallazgo frecuente intestinal. Es necesario reconocer que algunos de estos ascaris se entuentran muertos por la importancia que tiene $\mathrm{cl}$ cadáver ascaridiano en intoxicaciones y convulsiones de la infancia.

Las 1nvestigaciones hechas por el doctor Alberto Guzmár en el páncreas para encontrar la cornificación idel epitelio en casos de pvitaminosis A o procesos de pancratitis $\mathrm{fi}_{\text {- }}$ brosa para explicar el Sprue o infantilismo intestinal no dieron resultado alguno. Tampoco las atrofias de la mucosa intestinal descritas como típicas de la pelagra o el Sprue no fueron reconocidas.

De parte del aparato urinario se pueden presentar los riñones normales o con una nefritis intersticial como ya se h. explicado anteriormente. Las cápsulas suprarienales dan lugar 
a una diversidad histopatológica cuyo estudio completo será darlo a conocer posteriormente.

En la caja toráxica generalmente se encuentran el tipo de bronconeumonia distelectásica o la simple congestión o edema. Otras veces bronconeumonias banales o abscendentes - abcesos pulmonares, neumonias crónicas, empiemas, etc.

La tuberculosis con todo su cortejo sintomático de la primera y segunda infancia es otra de las infecciones que con mayor frecuencia se encuentran en estos cuadros carenciales. Es de hacer notar en esta infección, fuera de las adenopatías mesentéricas y ulceraciones tuberculosas que se forman en el último tiempo del cuadro, la degeneración hepática, hígado grasoso, órgano degenerado que contribuye en gran parte a la producción de estos cuadros carenciales o caquécticos.

El corazón se presenta más bien chico sin ninguna alteracjón digna de anotar; lo mismo los vasos.

En la caja craneana y en la médula no encontramos sino en los casos tipicos de pelagra las infiltraciones pigmentarias que se encuentran en algunas regiones del encéfalo, médula y ganglios espinales.

En las extremidades los buesos presentan ya sea alteraciones raquiticas u osteoporóticas que ninguna especifidad tienen sino representar lo que en las radiografías denominan los americanos tipos de hueso como vidrio esmerilado.

En los órganos de los sentidos, el examen de la conjuntiva es interesante apreciar su engrosamiento y sus células a veces cornificadas. En la mucosa bucal y nasal no hemos observado esta generación de cornificación que hablaría eil favor de una avitaminosis $A$.

\section{Diagnóstico}

En aquellas formas de iniciación, al comienzo puede prestarse su diagnóstico a dificultades. Pero la anamnesis puede ser utilísima en este caso por cuanto puede despistarse una alimentación carenciada, Por otro lado, la alteración de la curva de peso, la laxitud de la piel y el de los músculos. la disergia, formula el diagnóstico de una distrofia. Pero en séguida las manifestaciones de edemas comprobadas por el exa. men y la hidrofila. el cambio de carácter, el cansancio, las perturbaciones digiestivas, vímitos, diarreas y aquella inapetencia tan caprichosa. como así ya la hipermelanosis, y el el purito y la hiperqueratosis acompañada del síntoma del rasquido, dan inmediatamente los medios necesarios para 
formular el diagnóstico de síndrome carencial. Más difícil es ya saber si fuera de él, hay una infección sobreagregada que impide la obsorción y aprovechamiento de la alimentación. Para eso los exámenes de las deposiciones, rayos, sangre y todos los recursos de laboratorio para ayudar a la clínica, nos van a dar la clave de este tipo de infección que contribuye a la gestación del cuadro deficitario.

Y'a una vez establecido el edema y extendiéndose éste. no queda sino descartar la posibilidad de un edema cardíaco - renal. La falta de hepato y esplenomegalia, de disnea y de clilatación dardíaca y de tonos cardíacos normales. de oliguria y los síntomas anteriormente descritos. melanosis, hiperqueratosis, descamación, prurito, signo del rasquido, etc., sirven para esclarecer el diagnóstico. Respecto al edema de causa renal, llama la atención la distribución de él en manguito o bota y la falta de compromiso de la cara, ya de por sí serviría para excluírlo; pero no es tan fácil a veces con el cxamen de orina que revela albuminuria cilindruria y hematuria. La falta de hipertensión $y$ de fenómenos de dilatảción cardiaca, eliminan esta probabilidad.

El edema caquéctico se hace a veces casi imposible distinguirlo del edema carencial, pues por lo demás, los dos tienen más o menos la misma causa. La alteración profunida del hígado o degeneración grasosa es una de las razones para la gestación del edema en ambos cuadros. En consecuencia, el bígado grande y palpable en pleno período edematoso babla en favor de la degeneración e infiltración grasa de este órgano. El hígado pequeño también puede estar degenerado. En ambos la desaparición del edema y aprovechamiento del alimento se traducen en un estacionamiento de su tamaño a diferencia del hígado reaccional que aumenta de volumen en estas condiciones.

Las reacciones de tuberculinas como medio de diferenciación diagnóstica no pueden efectuarse en estos casos en los lugares acostumbrádos, como el antebrazo. Es la región del hombro en la parte anterior (Petruchsky) o la región anterior del tórax en donde se practica un Pirquet al cual se cubre con tela emplástica o unla cutirreacción de Volmer.

En general, con nuestro conocimiento sintomático regional, nos es dable con facilidad emitir el diagnóstico del cuadro carencial pero no así de la enfermedad acompañante a coadyudante. la cual con un examen clínico minucioso y exámenes de laboratorio, podemos desentrañar aquella en- 
frrmedad que directa o indirectamente contribuve a este trastorno metabólico.

\section{Profilaxia}

Cae de su propio peso que la prevención de estos sindromas carenciales reside en la alimentación completa, bien correlacionada, que suministre el coeficiente energético propio a la edad y peso del niño. Junto a esto las vitaminas correspondientes. Para contribuir a este desideratum hay necesidad de establecer una serie de medidas políticas, econónicas, sociales, como asi el de mejorar la cultura del pueblo en materia de alimentación. La necesidad primordial es que el Gobierno facilite al proletariado los alimentos básicos como leche, buevos, queso y leguminosas en una forma poco dispenciosa y al alcance de todos. Para ello deben poner en práctica las medidas correspondientes a establecer el libre intercambio americano de estas materias primas alimenticias. Para ello, además. debe recurrirse a un política que tenga por programa estimular la vialidad americana para que así el transporte de estos productos sea facilitado y entregado fresco an manos del consumidor. Sólo con estas directivas se podría mantener al pueblo en el mínimum de alimentación., pero racional y completa.

Estimular la alimentación curativa a base de leches icidas (leche albuminosa, babeurre), quesillos, jaleas, frutas verduras cocidas, etc., para las diarreas de cierta cronicidad y que no requieren de una alimentación hidrocarbonada sino que para mejorat aparentemente las heces.

Fuera de ello, el tratamiento de enterocolitis por medio te la bemoterapia, transfusiones sanguíneas, sirve para evitar estos derrumbes carenciales. Por ello es recomendable este sistema de tratamiento.

El uso de las vitaminas comerciales sintéticas llenan indicaciones durante el verano en que se requiere suministrarlas por la restricción alimenticia debido a las diarreas.

\section{Tratamiento.}

Difícil se hace ya el tratamiento en el hogar del niño porque en primer término se trata de una familia en un estado precario económicamente, habitaciones estrechas, antihigiénicas, de mayor convivencia. La alimentación la madre 
no puede como llevarla a cabo por la resistencia que ofrece el niño a ella y es de imprescindible necesidad que sea otra la persona y no la madre quien suministre la dieta. Además. en gran número de estos nínos existe un temor a que continúe el estado de inanición, con lo cual sobrevienen anomalías er. el equilibrio ácido básico, por los consabidos peligros y los necesarios tratamientos que no se justifican en la casa. Por eljo aconsejo tratamiento hospitalario por personal de médi$\cos y$ enfermeras idóneos en estos casos, por cuanto la falta de práctica en el tratamiento puede ocasionarle hasta la muerte. El primer día el niño se somete a una alimentación de lechè albuminosa o eledón o pelargón, una cantidad de 600 gramos de solución de $10 \%$ con $5 \%$ de hidratos de carbonos, como azúcar $y$ soxhet, o soxhet solo al cual se le puede agregar para darle mayor sabor unas gotas de té o café. Fuera de ésto, puede suministrarse y'a galletas o pan. Los vómitos que son el mayor escollo en este período para la alimentación deben considirarse como tipo neuropático (resistencia a la alimentación) o debidos a una atonia gástrica, con disminución o falta de ácido clorbidrico o jugo gástrico. En consecuencia, la inyección de luminal 0.05 y la suministración de 10 gotas de ácido clorhídrico repartidas en 21 día, contribuyen eficazmente a bloquear este síntoma. $\mathrm{Pe}$ ro otras veces continúa el síntoma vómito a pesar que se cambia la alimentación a una exclusivamente hidrooarbonada como crema de arroz o dieta hiperazucarada de $15 \%$ de soxhlet. Aquí el sintoma vómito representa un cuadro métabólico grave acidótico el cual hay que contrarrestar con inyecciones de suero clorurado intravenoso al $10 \%$ unos 10 a 20 cc. y suero glucosaldo al $15 \% 20$ cc. intramuscular. También las transfusiones sanguíneas. $10 \mathrm{cc}$. por kilo de peso como así las inyecciones de plasma de 30 a $50 \mathrm{cc}$. por kilo de peso. en este momento representan medidas salvadoras. La insulinia no debe colocarse por el temor a las grandes hipoglicemias. Ýa se dijo que existía a las 48 horas de iniciado el tratamiento. una hipoglicemia que hay que considerar por el estado de adinamia que se presenta en estos casos, de abí las indicaciones del suero glucosado. Como el cambio alimenticio es tan brusco, suspendiendo la sal y agregando el hidrato de tarbono la albúmina y cietta cantidad de grasa. el niño se nota más apático, decaido, molesto, el enfriamiento de las extremidades es grande por lo cual hay que rodear de botellas de agua caliente y emplear tónicos cardíacos comó base de cardiazol, coramina, cafeína, etc. 
Después de ingerir los 600 gramos de leche albuminosa. se va concentrando rápidamente el hidrato de carbono y agregando ya puré de legumbres o verduras sin sail. Ya al tercer o cuarto día y siendo el niño mayor de un año tres meses se le presenta el dispositivo antedicho, un plato con carne molida, papas fritas en aceite o arroz, huevo duro cortado en pequeños trozos y todo esto el niño generalmente lo come con la mano sin necesidad de utensilios para el objeto. Los plátanos y manzanas constituyen elementos de primordial imporrancia para su alimentación antes de dar jugos de frutas. En resumen la alimentación está basada en dar un alimento albuminoso con poca sal e hidratos de cakbonos en dilución y baja al principio para después aumentarla rápidamente. En seguida dar verduras, legumbres, carne, huevos y frutas a pesar de las deposiciones que en el número de 5 hasta 8 pueden tener, sin que esto signifique una razón para no impedir la alimentación completa. Cuando ya tiene la ración calórica o dieta completa, comienza a ostentarse el vientre balonado de la enfermedad celíaca el cual va desapareciendo poco a poco con el régimen y alimentación completa prolongada por meses y aun años. El uso de quesillos y alimentos antifermentativos como jalea, cliara de huevo, carne y ciertas leguminosas como lentejas, son necesarios para combatir cierto estado de dispepsia ácida que perdura a veces en estos casos. A pesar de todos estos regimenes, estos niños tienen durante la convalecencia recaidas con pérdidas bruscas de peso e inapetencia temporales que es necesario salvar para no caer luego en el mismo estado primitivo. En las filigranas alimenticias, está a veces la habilídad del médico y en muchas ocasiones la aceptación y tolerancia individual de un régimen alimenticio representa su medio curativo. No se debe olvidar en estos casos de emplear la sopa de malta. hidrato de carbono que junto a su acción vitamínica contribuye a las mejorias de la laxitud muscular, del crecimiento y del estado general.

Las transfusiones a veces deben prolongarse de un número de 6 hasta 10 por los resultados tan benéficos y eficientes que esta medida terapéutica nos los da en estos cuadros. Su medio de curación de las infecciones, la estimulación al sistema retículo-endotelial, el aumento de la proteina $y$ otros elementos ya preparados que en estra forma se dan, son factores esenciales para el tratamiento. Desgraciadamente no 
tenemos suficiente práctica con las transfusiones de plasma.

Para ratificar la mejoría de estos cuadros se necesita una convalecencia sumamente larga, a veces a tal extremo que tres mèses después pueden observarse aún alteraciones de las proteínas sanguíneas y la hidrofilia, lo que explica que perdura aún la alteración del metabolismo acuoso y en consecuencia, hay que supervigilar que estos casos no vayan a caer de nuevo en un régimen de hambre albuminosa, grasa y vitamínicas para no observar pronto la recidiva o recaída.

Principal hincapié de hacerse en que al iniciarse la dieta curativa no se debe mirar el cuadro como una avitaminosis o poliavitaminosis. Debido a ésto no he citado aún el empleo de estas substancias esenciales. En gran parte van en el alimento y como dice Stepp en elios van acondicionados por la naturaleza para que sean mejor aprovechados y utilizados en las dosis necesarias. Pero en estos niños tenemos que una vez que se inicia el crecimiento se nos viene encima el raquitismo. En consecuencia debemos usar una dosis de 10.000 unidades diarias para que eso no suceda. Lo mismo para la avitaminosis $A$, debe darse en dosis de la quinta parte de la attcerior. El jugo de frutas debe implantarse ya después de algunos días de establecido el régimen completo. Si hay idioEincrasia, dar ácido ascórbico 50 milígramos diarios. La vitamina B1 o cloruro de thiomina se da unos $10 \mathrm{mgrs}$. al día. sólo en el caso que séa necesario como por ejemplo en la anorexia prolongada, en aquellos trastornos de disquinesia intestinal, etc. Mucho más importante y prático considero las inyecciones de extracto hepático total como el Beanemol inyectable 5cc. intramuscular diarios con lo que se observa niejoría del apetito, de la anemia y del estado genera'.

En niños mayores sobre todo si presentan síntomas de pelagra o diarrea tipo Sprue, la administración de la levadu ra fresca de cerveza, unas 3 cucharaditas al dia, cuando ésta es bien tolerada y no produce vómitos, su efecto es bastante satisfactorio. Deliberadamente he colocado la suministración diel anterior antes del ácido nicotínico, pues consicero que ese medicamento no me ha suministrado los efectos tan sorprendentes que relata Spies y colaboradores. Es perfectamente tolerade y la dosis de 200 milígramos diarios nos han satisfecho. Pero es de hacer notar que las manifestaciones pelagrosas de la piel desaparecen rápidamente ya una vez instituída la alimentación completa $y$ antes de dar las vitaminas. Por eso que soy un poco escéptico sobre este tratamiento de Spies.

Queda aún un punto a dilucidar y es la curación de las diarreas tipo Sprue que con frecuenicia acompaña a estos 
cuadros. En estas diarreas hay a veces presencia de lamblias que de por si mantienen este sintoma. La ađministración de arsenicales como el Stovarsol y el Paroxil y Atebrina mejoran grandemente en algunos casos estas dierreas, lo cual es necesario tomar en consideración.

Respecto a los áscaris somos partidarios de abstenernos de toda medicación y esperar que sólo con la mejoría del estado general y del medio intestinal vayan eliminándose espontáneamente. Si después de un tiempo se apreciara gran cantidad de ellos y que éstos no salieran y por este motivo comprometieran el estado general, entonces se podía resolver una cura de aceite de Quenopodio o Bepermina Bayer.

Los empleos de la sulfanilamida y sulfapiridina pueden establecerse siempre que se hagan combinados con hemoterapias o transfusiones sanguíneas. Me inspiran temores su empleo sin las medidas anteriores. 